\title{
PROGRESSIVE IN'TERSTITIAL HYPERTROPHIC NEURITIS OF CHILDHOOD OF DEJERINE AND SOTTAS. REPORT OF A CASE*
}

\author{
WALTER F. SCHALLER, M.D. \\ SAN FRANCISCO
}

This rare disease was first described as an independent affection by Dejerine and Sottas. ${ }^{1}$ Previous to their publication Gombault and Mallet ${ }^{2}$ published the account of an observation of a patient having the characteristics of this affection, but they considered it as a case of tabes. There are but three autopsies recorded, those of Dejerine and Sottas, ${ }^{1}$ of Dejerine and Thomas ${ }^{3}$ and the case of Pierre Marie studied by Boveri. ${ }^{4}$

This disease has been studied chiefly in France. The original descriptions of Gombault and Mallet, Dejerine and Sottas and a subsequent publication by Dejerine ${ }^{5}$ give a complete and thorough description of the affection from a pathological as well as a clinical standpoint. A good account is found in the work of Dejerine and Thomas, ${ }^{6}$ and it is briefly considered by Pierre Marie ${ }^{7}$ in his book on neurology. Short accounts are also found in v. Hutinel's System, ${ }^{8}$ in the work of Pfaundler and Schlossmann $^{9}$ and in Osler's Modern Medicine. ${ }^{10}$ Sainton $^{11}$ takes up the question of differential diagnosis and holds very strongly for the independent classification of the affection. This has been brought in question by Marinesco, ${ }^{12}$ Beduschi ${ }^{13}$ and Raymond, ${ }^{14}$ who believe that the affection is

*From the Neurological Clinic, Department of Medicine, Leland Stanford Jr. University, San Francisco, Cal.

*Manuscript submitted for publication July 24, 1912.

1. Dejerine and Sottas: Soc. biol., séance du 18 mars 1893. Mem. Soc. de biol., 5, 9 séries 1893, p. 63.

2. Gombault et Mallet: Cn cas de tabès avant débuté dans l'enfance. Autopsie. Arch. de méd. expér., 1889, p. 385, pl. x.

3. Dejerine and Thomas: Soc. neurol., June 5, 1902. Quoted by Marie in La Pratique Neurologique.

4. Piero Boveri. München. Med. Wchnschr., June 6, 1911, p. 1238.

5. Dejerine: Rev. de méd., November, 1896, xvi.

6. Dejerine and Thomas: Maladies de la Moelle Epiniére, Paris, 1909.

7. Marie, Pierre: La Pratique Neurol., Paris, 1911, p. 696.

8. v. Hutinel: Les Maladies des Enfants. Paris, 1909, v, 426.

9. Pfaundler and Schlossmann: Handbuch der Kinderheilkunde, Leipzig, 1910, 4 Band, S. 173.

10. Osler's Modern Medicine: Philadelphia, 1903, vii, 113.

11. Sainton: Thèse de Paris 1889. Quoted by Dejerine, Mal. de la Moelle Ep., p. 776 .

12. Marinesco: Arch. de path. exper. et comparée, 1895, quoted by v. Hutinel.

13. Beduchi : Riv. di patholog. nervs. ment., 1906, quoted by v. Hutinel.

14. Raymond: Cliniques, 1903, quoted by v. Hutinel. 
identical with, or forms a type of, the myelopathic muscular atrophy type. Charcot-Marie. Dejerine, Sainton, Pierre Marie and Boveri hold for the independence of the affection and claim that the hypertrophy of the nerves, which constitutes one of the most striking characteristics of the disease, is an early pathological finding and not a late development accompanying muscular atrophy and deformity. I believe that the case that I am to report will throw some light on this question.

In Germany, Brasch ${ }^{15}$ presented two doubtful cases in Berlin in 1903, which he believed to be subforms of this disease. There was, however, no distinct hypertrophy of the peripheral nerves in his cases; and in the discussion which followed Remak thought that they fell rather into the classification of the type of muscular atrophy described by Hoffmann of Heidelberg (progressive neural muscular atrophy).

\section{DESCRIPTION OF DISEASF}

It has its commencement in childhood between the eighth and fourteenth year and is frequently a family affection. It is characterized by a progressive course, by ataxia, by muscular atrophy and a marked disturbance of the sensibility together with hypertrophy of the nerve trunks, which is the distinguishing feature of the disease. The muscular atrophy commences in the extremities and the inferior extremity is always involved before the superior. The atrophy of the small muscles of the hands is of the Aran-Duchenne type. The atrophy and the malformation of the feet is such as is met with in Friedreich's ataxia. Fibrillary contractions of the muscles have been occasionally noted. The cutaneous and tendinous reflexes are abolished. The muscular response to the faradic and galvanic currents is diminished; reaction of degeneration is occasionally noted. All forms of sensibility are markedly affected. The walk is that of steppage, but not typically so, as the presence of a certain amount of atcxia produces a very unsteady gait. The sign of Romberg is present and there is a marked ataxia in the finger-nose and heel-knee tests. The reaction of the pupil to light is slowed or entirely absent while the reactions to accommodation and to convergence are conserved. Thus the Argyll Robertson pupil has been observed. The sphincters are intact. The hypertrophy of the nerves is perhaps the most striking feature of the clinical picture. Not only are the great nerve trunks of the extremities involved, but also the cutaneous branches. To quote the description of Dejerine:

It is a uniform hypertrophy without nodosity or any unevenness; the consistency of the nerves is greatly increased and gives to the palpating finger the impression of the arteries of a cadaver previously injected with gelatin. The pressure on the nerve trunks, even though it be great, causes no pain. In the hypertrophic interstitial neuritis there is a veritable analgesia of the nerve trunks to pressure and to the electric current.

15. Brasch: Berlin Gesellsch. f. Psychiat. u. Nervenkr., July 13, 1903. Reported in Neurol. Centralb]., 1903, No. 15, p. 748. 
Due to the atrophy of the muscles which tend to support the spinal column kyphoscoliosis has been noted. Exophthalmos, scanning speech, intention tremor and nystagmus may be present.

Boveri" has described two clinical types of the affection:

1. Type Gombault-Dejerine-Sottas.-Myosis, Argyll Robertson pupils, lightning pains, motor ataxia, fibrillary twitchings, nystagmus, absence of intention tremor, of scanning speech and of exophthalmos and the presence of general muscular atrophy.

2. Type Pierre Marie.-No true Romberg, no myosis, no true Argyll Robertson pupils, only slow reaction to light, no lightning pains, motor ataxia, nystagmus or fibrillary twitchings. Intention tremor, scanning speech and exophthalmos present. Muscular atrophy limited to the lower extremity and barely indicated in the hands. This type therefore presents points of similarity to multiple sclerosis.

\section{PATHOLOGICAL ANATOMY (DEJERINE)}

The cranial nerves are larger than those of a normal individual, but are far less hypertrophied than the spinal nerves. The sympathetic system takes a prominent part in the hypertrophy. The ganglia of the posterior roots are notably enlarged. The spinal cord is not altered in volume, but there is an atrophy of the posterior columns and an accompanying leptomeningitis in this locality. The dura mater about the cord is not altered. Histologically, the nerves show both interstitial and parenchymatous changes. The interstitial changes are typical. The proliferation of fibrous tissue instead of taking place between the nervous elements in the endoneurium, as in certain other forms of neuritis, takes place about the individual nerve fiber or about several fibers forming an isolating sheath, without, however, the endoneurium being affected. This sheath of connective tissue is disposed concentrically about the nerve fiber much after the fashion of the layers of an onion. In the peripheral nerves one sees few nuclei; on the contrary the spinal roots show abundant nuclei of the embryonic type and vacuoles are numerous. The posterior horns of the gray matter in the cord are small. The cells of the anterior horn studied by Nissl's method show a diminution in number and some are found atrophied and the chromatic network is hardly visible.

\section{DIFFERENTIAL DIAGNOSIS}

This affection must be differentiated from the Charcot-Marie type of spinal muscular atrophy, from Friedreich's ataxia, from an ordinary peripheral neuritis and from juvenile tabes. I saw a case in the service of Pierre Marie in Bicetre, which was considered to be a case of Friedreich's ataxia until the discovery of the hypertrophic nerves showed the error in diagnosis. The first described case of this affection was classed as a juvenile tabes. The case $I$ have to report resembles tabes very much in its clinical aspect. The following is the report of the case: 


\section{CASE REPORT}

A. B., aged 20, native of San Francisco, of German parentage, newsboy, came to the out-patient clinic in January, 1912, complaining of trouble in walking, and of weakness.

Family History.-Father and mother living and well. The mother gave no history of abortion or miscarriage. The patient has two sisters both of whom are well. An examination of these sisters as well as of the mother presented no evidence of the disease in any one of them. The father was not examined, but he is said to be in good health; and there was no history of a similar affection being present in any branch of the family.

Previous History.-The birth was normal and the infant was normal in every respect. He was fed at the breast for a period of nine months. Dentition com: menced at five months, he began walking at 13 months and began to talk at 2 years of age. He had measles, whooping-cough and chicken-pox between the seventh and the ninth years.

Present History.-The present trouble began seven years prior to this report, when he was seized with an attack of general weakness and loss of ambition. The mother thinks the illness commenced from bathing in a contaminated swimming pool. Other children in the vicinity became sick from this same cause she thinks; some took typhoid fever and others had diphtheria. At the onset of his trouble fever was not present and a doctor was not consulted until several months later. At this time failing strength was noticed, which first began in the legs and extended to the arms and hands. This advanced to such a stage that he could not care for himself. There was no trouble with the sphincters. The doctor whom he consulted prescribed a Kneipp water cure. Patient states that while under this treatment he improved slowly for one year. After 1906, the patient's condition remained about the same until September, 1911, since which time the trouble has become worse. The principal complaint of the patient is that the legs feel heavy and get tired easily and that he is unsteady on his feet. He never has had pain. He has difficulty in performing the finer manipulations, such as buttoning his coat and tying his tie. Writing has become difficult and unsteady. There is no disturbance in articulation or deglutition. The sphincters function normally. Sight and hearing are unaffected and the mentality has in no wise suffered. The speech is slow and measured, but the mother states that this has always been so. There is no complaint of headache, vomiting or dizziness. The appetite is good. Constipation is apt to be the rule. The weight has not varied of late; there is no cough or night sweats. Patient leads a very quiet moderate life, living with his parents. Denies all venereal infection and does not use tobacco or indulge in alcohol.

Status, January 26, 1912.-A fairly well nourished young man below the average height. Weight $1151 / 2$ pounds. Pulse 78 , regular and of good volume and tension. The face presents a sallow and rather bloated appearance with puffiness about the eyes. The neck is very broad and thick set. The upper lip is somewhat projected, the labial commissure is transverse and the smile is transverse. There are numerous moles about the face. The spine shows a moderate lateral scoliosis. There are several patehes of pityriasis versicolor on the chest. The tongue is hypertrophied, the hypertrophy being of the entire organ and also of the individual papillæ; there is a scattered but well-marked exfoliating dermatitis present, shown by numerous slightly elevated patches with a fine sinuous border, forming an incomplete ring. These patches change their position from day to day. No scars suspicious of syphilis are seen on the surface of the body or in the nasopharynx. The tonsils are enlarged. There is no noticeable atrophy of any of the muscles. There is no superficial glandular enlargement. No trembling of the hands. The strength in the hands is diminished. Dynamometer readings: right hand $22 \mathrm{~kg}$., left hand $22 \mathrm{~kg}$. (pressure). The power in the arms, forearms, legs and thighs is fairly well conserved, but the flexors of the foot are decidedly weak while the extensors are not so affected. The walk is that of the steppage gait with at the same time an ataxia and a certain incoordination and swaying. In the pointing movements of the hands and of the feet there is some error when the eyes are open, and this is much increased when the eyes are closed. There 


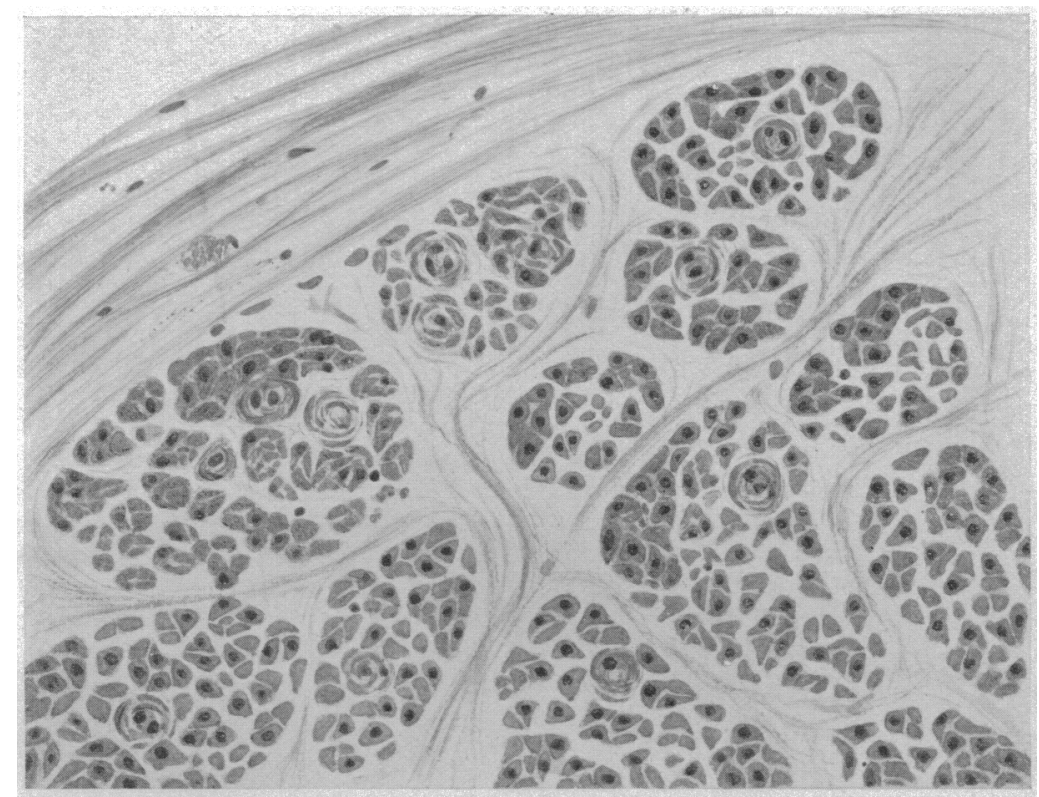

Hypertrophic interstitial neuritis. Transverse section of a superficial nerve of the cervical plexus measuring $3.5 \mathrm{~mm}$. in diameter. Stained by van Gieson's method. The individual nerve fiber is seen surrounded by a sheath of connective tissue consisting of a number of layers disposed concentrically. 
is some adiadochokinesis in both hands, but this is not pronounced. There is a distinct Romberg, but no asynergia or "mouvements démesurés" (Babinski).

Reflexes: The knee jerks, ankle jerks and radial reflexes are absent. The triceps reflex is present. The abdominal reflexes are present and the plantar reflex is in flexion. The anal and cremasteric reflexes are absent. On percussion of the muscles the muscular reflex is everywhere present.

Sensibility: The sensibility is markedly affected in the extremities but not about the trunk. The sensibility to touch, to heat and cold, and to pain shows a diminution which is more pronounced at the periphery of a member than at its base. The deep sensibility is likewise affected. The pressure sense, sense of position, notion of the position of the segments of a member, including the muscular and articular sensibility, and the osseus sensibility, are impaired. There is a disturbance of the stereognostic sense. Pallesthesia as tested with the Luer fork shows perception of the vibration between 6 and 7 over the lower radius and ulna and 5 plus over the internal malleolus-figures considerably below the normal.

Hypertrophy of the nerves: The nerve trunks of the axilla, the ulnar nerve at the bend of the elbow, superficial branches of the cervical plexus, cutaneous branches on the dorsal surface of the forearms and the external popliteal nerve are markedly hypertrophic and easily palpable. 'They are not sensitive to pres. sure and on palpation are found to be free from unevenness and may be rolled under the finger like a sclerotic artery. The ulnar nerve at the bend of the elbow feels about the size of a large goose quill.

UInar Nerve Reflex: If the patient be placed in the anatomical position with the palms of the hands anteriorly and the arm be percussed above the olecranon at the inner side, a brusque movement of pronation takes place due to the percussion of the enlarged ulnar nerve and the consequent contraction of the flexor carpi uInaris. This is found constantly on the left side.

Cranial Nerves: The pupils react well to light and accommodation, are equal in size and regular in contour. The eye movements are normal, there is no contraction of the field of vision and no nystagmus. Report from the eye clinic: "Disks pale in color but normal." Taste and smell are normal. No anesthesia about the distribution of the fifth nerve and no involvement of the facial nerve. Sense of hearing is acute in both ears. The corneal and pharyngeal reflexes are both present. The tongue is not deviated from the mid-line but there is a slight trembling. No trouble in deglutition or articulation.

Electrical Reactions of the Muscles: The electrical reactions of the muscles show an alteration consisting of a hypo-excitability to both the faradic and galvanic currents. In certain muscles an incomplete reaction of degeneration is found. Thus in the extensor communis digitorum and the extensor longus digitorum there is a decided slowing of the contraction to the galvanic current with inversion of the formula: ACC being greater than KCC. In the trapezius, deltoid, biceps, triceps, flexor profundus digitorum, first dorsal interosseus of the hand, biceps femoris, quadriceps femoris, tibialis anticus and flexor longus digitorum there is no inversion but a slight slowing of the contraction, not so marked as in the case of the extensors, where the contraction is almost vermicular.

In the supinator longus, peroneii, flexor longus hallucis, extensor proprius hallucis, semimembranosus, semitendinosus, gastrocnemius and soleus the contraction is quick. In every case the faradic excitability is conserved.

An examination of the heart, lungs and abdomen shows normal conditions. The liver is not enlarged and the spleen cannot be palpated. Over the body generally the muscles give a sense of increased tonicity. No fibrillary twitchings of the muscles are observed. The urine shows no albumin nor sugar and a microscopical examination of the sediment shows no casts. 
Blood: Red cell count, 4,350,000; white cell count, 4,600. Hemoglobin, 96 per cent.; color index, 89 per cent. Differential white count, polymorphonuclear leukocytes, 58 per cent.; lymphocytes, 40 per cent.; large mononuclear leukocytes, 2 per cent. Wassermann reaction in the blood negative.

Microscopical Examination of an Excised Nerve: One of the enlarged superficial cervical nerves was excised for microscopical examination. This nerve, which was visible beneath the integument, measured $3.5 \mathrm{~mm}$. in diameter in the fresh specimen. Stained sections showed the typical picture of interstitial connective tissue proliferation about the individual nerve fiber. In one place in the specimen, not pictured in the illustration, there is a proliferation of the endoneurium with round-cell infiltration, but this is not characteristic of the general appearance of the specimen. The following is the report of the pathologist, Prof. William Ophüls:

Cross sections through the nerve show a moderate fibrous thickening of the perineurium. There is also in places quite a marked round cell infiltration of the nerve itself with diffuse thickening of the endoneurium. Around many of the nerve fibers the sheath of Henle is thickened which has led to the formation of concentric masses of connective tissue around them. Diagnosis, chronic interstitial hypertrophic neuritis.

\section{TREATMENT}

Under arsenic in the form of Fowler's solution in moderate doses and the employment of the constant galvanic current, considerable improvement was obtained. It is probable, however, considering the chronic and progressive character of the disease, that this improvement is only temporary; but its course may extend over many years and the prognosis as far as life is concerned is good.

\section{DISCUSSION}

The beginning of the affection in childhood, the marked hypertrophy of the nerves, the ataxia, the loss of muscular strength, the change in character of the electrical muscular reactions, the marked disturbance of the sensibility and the histopathological findings in the hypertrophied nerve fiber itself establishes the diagnosis of this case on a clinical as well as pathological basis. The process is evidently in the early stages, as a number of symptoms such as the atrophy of the muscles, Argyll Robertson pupils and deformity, which may develop at a later stage, are now absent. In this connection I wish to emphasize the early and great hypertrophy of the nerve trunks; for some have held that this occurs only in the later stages of the condition or even go further and believe that in the presence of a marked atrophy the nerve trunks stand out more prominently and are not really hypertrophied, but only apparently so. From our observation of this case this hypertrophy of the nerve trunks which surpasses that seen in two other cases much more advanced, leads us to believe that it plays an important part in the clinical picture, and to hold with Dejerine and others that we have to deal here with a distinct affection. 